\title{
Diagnostic significance of gadolinium-DTPA (diethylenetriamine penta-acetic acid) enhanced magnetic resonance imaging in thrombolytic treatment for acute myocardial infarction: its potential in assessing reperfusion
}

E E van der Wall, P R M var: Dijkman, A de Roos, J Doornbos, A van der Laarse, V Manger Cats, A E van Voorthuisen, N A A Matheijssen, A V G Bruschke

\begin{abstract}
The diagnostic value of gadoliniumDTPA (diethylenetriamine penta-acetic acid) enhanced magnetic resonance imaging in patients treated by thrombolysis for acute myocardial infarction was assessed in 27 consecutive patients who had a first acute myocardial infarction (14 anterior, 13 inferior) and who underwent thrombolytic treatment and coronary arteriography within 4 hours of the onset of symptoms. Magnetic resonance imaging was performed 93 hours (range 15-241) after the onset of symptoms. A Philips Gyroscan (0.5 T) was used, and spin echo measurements (echo time $30 \mathrm{~ms}$ ) were made before and 20 minutes after intravenous injection of $0.1 \mathrm{mmol} / \mathrm{kg}$ gadolinium-DTPA. In all patients contrast enhancement of the infarcted areas was seen after Gd-DTPA. The signal intensities of the infarcted and normal values were used to calculate the intensity ratios. Mean (SD) intensity ratios after Gd-DTPA were significantly increased $(1.15(0.17) v 1.52(0.29))$. Intensity ratios were higher in the 17 patients who underwent magnetic resonance imaging more than 72 hours after the onset of symptoms than in the 10 who underwent magnetic resonance imaging earlier, the difference being significantly greater after administration of GdDTPA (1.38 (0.12) $v 1.61(0.34)$. When patients were classified according to the site and size of the infarcted areas, or to reperfusion $(n=19)$ versus non-reperfusion $(n=8)$, the intensity ratios both before and after Gd-DTPA did not show significant differences.
\end{abstract}

Magnetic resonance imaging with GdDTPA improved the identification of acutely infarcted areas, but with current techniques did not identify patients in whom thrombolytic treatment was successful.

Magnetic resonance imaging of the heart offers the potential for the non-invasive detection, localisation, and measurement of acutely infarcted myocardial areas. ${ }^{1-3}$ Infarcted areas can be identified by local wall thinning, increased flow signal in the ventricular cavity, and increased signal intensity in the infarcted area. ${ }^{45}$
In particular $T_{1}$ and $T_{2}$ relaxation times are prolonged in the oedematous infarct zone. ${ }^{6-8} \mathrm{~T}_{2}$ prolongation seems to predominate and therefore an increased myocardial signal intensity is best appreciated on $T_{2}$ weighted images obtained by long repetition times and long echo times with the multi-echo technique in a spin echo sequence. ${ }^{239}$ However, in many cases the contrast has been suboptimal because of the inherent low signal to noise ratio. Recently, the use of gadolinium (Gd)-diethylenetriamine penta-acetic acid (DTPA) as a paramagnetic contrast agent has been proposed for better delineation of areas of infarcted myocardium. ${ }^{10-}$ ${ }^{12}$ Gd-DTPA significantly shortened the $T_{1}$ relaxation time of irreversibly injured canine myocardium and so increased the signal intensity of the infarct in relation to normal myocardium. ${ }^{13-15}$ Previous studies in patients with acute myocardial infarction have shown that administration of Gd-DTPA resulted in significant contrast enhancement of infarcted myocardial areas, with maximal contrast enhancement being obtained 20-30 minutes after administration. ${ }^{12} 16$ Experimental studies have shown that Gd-DTPA enhanced magnetic resonance imaging can distinguish between reperfused and non-reperfused myocardium in acute myocardial infarction. ${ }^{17-19}$ This might be of clinical importance because currently there are no reliable methods of assessing the results of coronary thrombolysis non-invasively. To test this diagnostic potential we examined the results of magnetic resonance imaging before and after administration of Gd-DTPA in 27 patients with acute myocardial infarction who underwent coronary arteriography and intracoronary administration of streptokinase within $\mathbf{4}$ hours of the onset of symptoms and in whom we therefore had unequivocal evidence on the occurrence of early reperfusion. As well as the effect of reperfusion we evaluated the influence of infarct size and site on myocardial signal intensity and we determined the time period in which Gd-DTPA gave the greatest enhancement.

\section{Patients and methods}

PATIENTS

Twenty seven patients ( 23 men, four women; mean age 52 years (range $30-75$ )) with acute myocardial infarction were studied by electrocardiographically gated magnetic resonance
The Netherlands.
The AA Leiden,

Accepted for publication 22 August 1989 
Individual results of streptokinase treatment and magnetic resonance imaging findings

\begin{tabular}{|c|c|c|c|c|c|c|c|c|c|c|c|}
\hline Case & $\begin{array}{l}\text { Age (yr) } \\
\text { and sex }\end{array}$ & $\begin{array}{l}\text { Infarct } \\
\text { site }\end{array}$ & $\begin{array}{l}\text { Infarct } \\
\text { artery }\end{array}$ & $\begin{array}{l}\text { Residual } \\
\text { stenosis (\%) }\end{array}$ & $\begin{array}{l}\text { Cumulative } \\
H B D H(U / l)\end{array}$ & $\begin{array}{l}\text { Time to } \\
\text { reperfusion } \\
(\text { min }) \dagger\end{array}$ & $\begin{array}{l}\text { From infarct } \\
\text { to } M R I \\
\text { (h) }\end{array}$ & $\begin{array}{l}\text { IR before } \\
G d-D T P A\end{array}$ & $\begin{array}{l}\text { IR after } \\
G d-D T P A\end{array}$ & $\begin{array}{l}\Delta I R \\
(\%)\end{array}$ & $\begin{array}{l}\text { Aspect } \\
\text { contrast }\end{array}$ \\
\hline $\begin{array}{l}1 \\
2 \\
3 \\
4 \\
5 \\
6 \\
7 \\
8 \\
9 \\
10 \\
11 \\
12 \\
13 \\
14 \\
15 \\
16 \\
17 \\
18 \\
19 \\
20 \\
21 \\
22 \\
23 \\
24 \\
25 \\
26 \\
27 \\
\text { Mean } \\
\text { SD }\end{array}$ & $\begin{array}{l}57 \mathrm{M} \\
30 \mathrm{M} \\
56 \mathrm{M} \\
46 \mathrm{M} \\
46 \mathrm{M} \\
47 \mathrm{M} \\
49 \mathrm{~F} \\
42 \mathrm{~F} \\
33 \mathrm{M} \\
65 \mathrm{M} \\
51 \mathrm{M} \\
57 \mathrm{M} \\
41 \mathrm{M} \\
60 \mathrm{M} \\
39 \mathrm{M} \\
68 \mathrm{~F} \\
75 \mathrm{M} \\
58 \mathrm{M} \\
50 \mathrm{M} \\
59 \mathrm{M} \\
49 \mathrm{M} \\
75 \mathrm{M} \\
70 \mathrm{~F} \\
46 \mathrm{M} \\
38 \mathrm{M} \\
51 \mathrm{M} \\
61 \mathrm{M} \\
52 \\
11\end{array}$ & $\begin{array}{l}\text { Inf } \\
\text { Inf } \\
\text { Inf } \\
\text { Ant } \\
\text { Ant } \\
\text { Ant } \\
\text { Inf } \\
\text { Inf } \\
\text { Inf } \\
\text { Ant } \\
\text { Ant } \\
\text { Inf } \\
\text { Ant } \\
\text { Ant } \\
\text { Ant } \\
\text { Ant } \\
\text { Inf } \\
\text { Inf } \\
\text { Inf } \\
\text { Ant } \\
\text { Inf } \\
\text { Inf } \\
\text { Ant } \\
\text { Ant } \\
\text { Ant } \\
\text { Ant } \\
\text { Inf }\end{array}$ & $\begin{array}{l}\text { RCA } \\
\text { LCX } \\
\text { LCX } \\
\text { LAD } \\
\text { LAD } \\
\text { LAD } \\
\text { RCA } \\
\text { RCA } \\
\text { RCA } \\
\text { LAD } \\
\text { LAD } \\
\text { RCA } \\
\text { LAD } \\
\text { LAD } \\
\text { LAD } \\
\text { LAD } \\
\text { RCA } \\
\text { LCX } \\
\text { RCA } \\
\text { LAD } \\
\text { LCX } \\
\text { RCA } \\
\text { LAD } \\
\text { LAD } \\
\text { LAD } \\
\text { LAD } \\
\text { LCX }\end{array}$ & $\begin{array}{r}91-99 \\
50-90 \\
50-90 \\
0-50 \\
50-90 \\
0-50 \\
91-99 \\
0-50 \\
91-99 \\
0-50 \\
50-90 \\
91-99 \\
0-50 \\
0-50 \\
0-50 \\
0-50 \\
91-99 \\
0-50 \\
0-50 \\
100 \\
100 \\
100 \\
100 \\
100 \\
100 \\
100 \\
100\end{array}$ & $\begin{array}{r}664 \\
2018 \\
542 \\
105 \\
1230 \\
1331 \\
590 \\
296 \\
534 \\
1471 \\
2137 \\
2108 \\
1234 \\
1374 \\
1051 \\
387 \\
822 \\
822 \\
1061 \\
1745 \\
685 \\
1238 \\
1509 \\
562 \\
282 \\
1350 \\
1135 \\
1048 \\
566\end{array}$ & $\begin{array}{r}55 \\
105 \\
105 \\
115 \\
130 \\
145 \\
150 \\
150 \\
160 \\
160 \\
170 \\
180 \\
185 \\
200 \\
210 \\
210 \\
240 \\
240 \\
180 \\
= \\
= \\
= \\
= \\
= \\
-\end{array}$ & $\begin{array}{r}98 \\
46 \\
41 \\
97 \\
63 \\
110 \\
99 \\
82 \\
113 \\
119 \\
48 \\
120 \\
241 \\
37 \\
97 \\
88 \\
44 \\
99 \\
64 \\
109 \\
179 \\
51 \\
15 \\
95 \\
58 \\
167 \\
134 \\
93 \\
49\end{array}$ & $\begin{array}{l}1.03 \\
0.93 \\
1.01 \\
1.07 \\
1.06 \\
1.35 \\
1.15 \\
1.00 \\
1.15 \\
1.07 \\
1.11 \\
1.18 \\
1.27 \\
1.02 \\
1.36 \\
1.65 \\
0.94 \\
1.44 \\
1.28 \\
1.00 \\
1.09 \\
1.15 \\
0.86 \\
1.13 \\
1.13 \\
1.15 \\
1.38 \\
1.15 \\
0.17\end{array}$ & $\begin{array}{l}1.43 \\
1.29 \\
1.29 \\
1.24 \\
1.23 \\
1.44 \\
1.21 \\
1.46 \\
1.31 \\
1.73 \\
1.41 \\
1.32 \\
1.58 \\
1.63 \\
2.13 \\
2.55 \\
1.31 \\
1.74 \\
1.40 \\
1.80 \\
1.52 \\
1.38 \\
1.31 \\
1.66 \\
1.51 \\
1.45 \\
1.73 \\
1.52 \\
0.29\end{array}$ & $\begin{array}{r}44 \\
39 \\
28 \\
16 \\
16 \\
7 \\
5 \\
46 \\
14 \\
63 \\
27 \\
12 \\
24 \\
60 \\
57 \\
55 \\
39 \\
21 \\
9 \\
80 \\
38 \\
20 \\
52 \\
47 \\
34 \\
26 \\
25 \\
33 \\
19\end{array}$ & $\begin{array}{l}\text { II } \\
\text { II } \\
\star \\
0 \\
\vdots \\
\text { II } \\
\text { II } \\
\text { II } \\
\text { I } \\
\text { I } \\
\text { II } \\
\text { II } \\
\text { I } \\
\text { II } \\
\text { II } \\
\text { II } \\
\text { I } \\
\text { I } \\
\text { II } \\
\text { II } \\
\text { II } \\
\text { I } \\
\text { II } \\
\text { II } \\
\text { II } \\
\text { II } \\
\text { II }\end{array}$ \\
\hline
\end{tabular}

Ant, anterior; HBDH, hydroxybutyrate dehydrogenase; inf, inferior; IR, intensity ratio infarct/normal tissue; $\Delta \mathrm{IR}=$ percentage change in intensity ratio; LAD, left anterior descending coronary artery; LCX, left circumflex coronary artery; MRI, magnetic resonance imaging; RCA, right coronary artery; $0=$ no contrast enhancement; I = homogeneous contrast enhancement, II = inhomogenous contrast enhancement. ${ }^{\star P o o r}$ image quality. †Time from streptokinase infusion to reperfusion in minutes.

Figure 1 Planes used for detection of myocardial infarction (transverse planes for anteroseptal infarction and sagittal planes for inferior infarction. $L V$, left ventricle, $R V$, right ventricle. imaging 93 hours (range 15-241) after the acute event (table). Seventeen patients were included in previous related studies. ${ }^{2021}$ In all patients a first transmural myocardial infarction was diagnosed on the basis of electrocardiographic $Q$ waves and a typical increase in cardiac enzymes. Immediately after electrocardiographic evidence of acute myocardial infarction was obtained, an intravenous dose of $750000 \mathrm{U}$ of streptokinase was given. The coronary arteriography was performed within 4 hours of the onset of symptoms. At catheterisation, an additional dose of $250000 \mathrm{U}$ streptokinase was usually administered into the infarct related artery. In 19 patients reperfusion was achieved; in eight patients the infarct related artery remained occluded. Ten patients underwent magnetic resonance imaging studies within 72 hours of the onset of symptoms (mean 47 hours, range 15-64 hours; group 1) and 17 patients underwent magnetic resonance imaging studies $>72$ hours (mean 120 hours, range 82-241 hours) (group 2) after the onset of symptoms. The cut off point of 72 hours was

Transverse

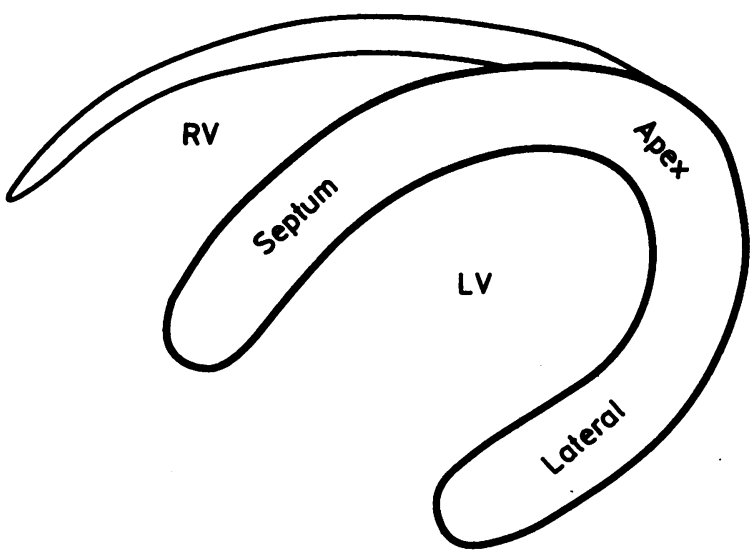

based on our policy to perform percutaneous coronary transluminal angioplasty within 72 hours in patients with signs and symptoms of residual ischaemia after thrombolytic treatment. Anterior wall infarction was present in 14 patients and inferior wall infarction in 13 patients. To measure infarct size we used cumulative $\alpha$ hydroxybutyrate dehydrogenase release up to 72 hours after the onset of symptoms. ${ }^{22}$ In our study, mean $\alpha$ hydroxybutyrate dehydrogenase release was $1048 \mathrm{U} / 1$ (range 105 to $2136 \mathrm{U} / 1$ ). Patients with an $\alpha$ hydroxybutyrate dehydrogenase release of $<1000 \mathrm{U} / 1$ were considered to have small to moderate infarctions (12 patients, mean 492 $\mathrm{U} / \mathrm{l}$, range 105 to $822 \mathrm{U} / \mathrm{l})$. Fifteen patients had large infarctions $(>1000 \mathrm{U} / \mathrm{l}$, mean $1432 \mathrm{U} / \mathrm{l}$, range 1051 to $2137 \mathrm{U} / 1)$.

MAGNETIC RESONANCE IMAGING TECHNIQUE

The magnetic resonance imaging studies were performed with an $0.5 \mathrm{~T}$ Philips Gyroscan. Four $10 \mathrm{~mm}$ thick slices were taken at a $5 \mathrm{~mm}$ slice interval. Sagittal planes were chosen for

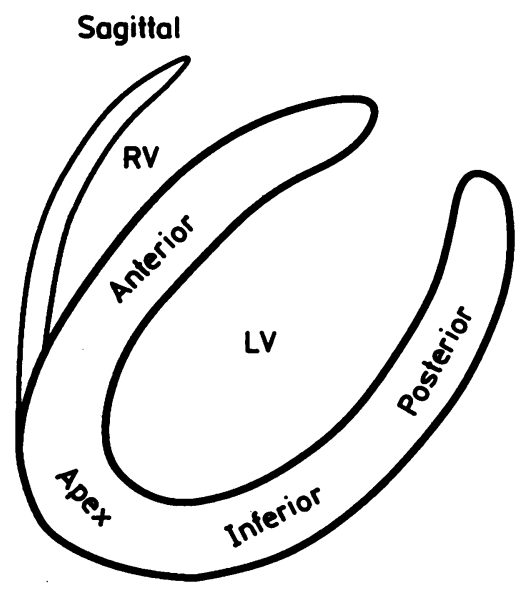


anterolateral or inferior infarction, and transverse planes for anteroseptal or posterolateral infarction (fig 1). The echo times were $30 \mathrm{~ms}$ and the repetition times were equal to the $R R$ interval. The trigger delay was $200 \mathrm{~ms}$ after the $R$ wave of the electrocardiogram. A matrix of $128 \times 256$ pixels was used for acquisition and the images were displayed with a $256 \times 256$ matrix. The field of view was $30-40 \mathrm{~cm}$.

After the baseline magnetic resonance imaging scans were performed, all patients received an intravenous injection of $0.1 \mathrm{mmol} \mathrm{Gd}$ DTPA/kg body weight. Since our previous studies showed maximal contrast in the first 15-25 minutes after Gd-DTPA administration, ${ }^{162021}$ the magnetic resonance imaging scans were repeated about 20 minutes after the administration of Gd-DTPA.

\section{IMAGE ANALYSIS}

The magnetic resonance imaging scans were visually assessed for the presence of signs indicative of myocardial infarction. The region with maximal contrast enhancement was considered to represent the infarcted area and the region without visual contrast enhancement was considered to represent normal myocardial tissue. The images were read by two independent observers blinded to patient identity. When they disagreed a third observer was consulted to reach a consensus. Quantitative evaluation of contrast enhancement was also performed by computer assisted determination
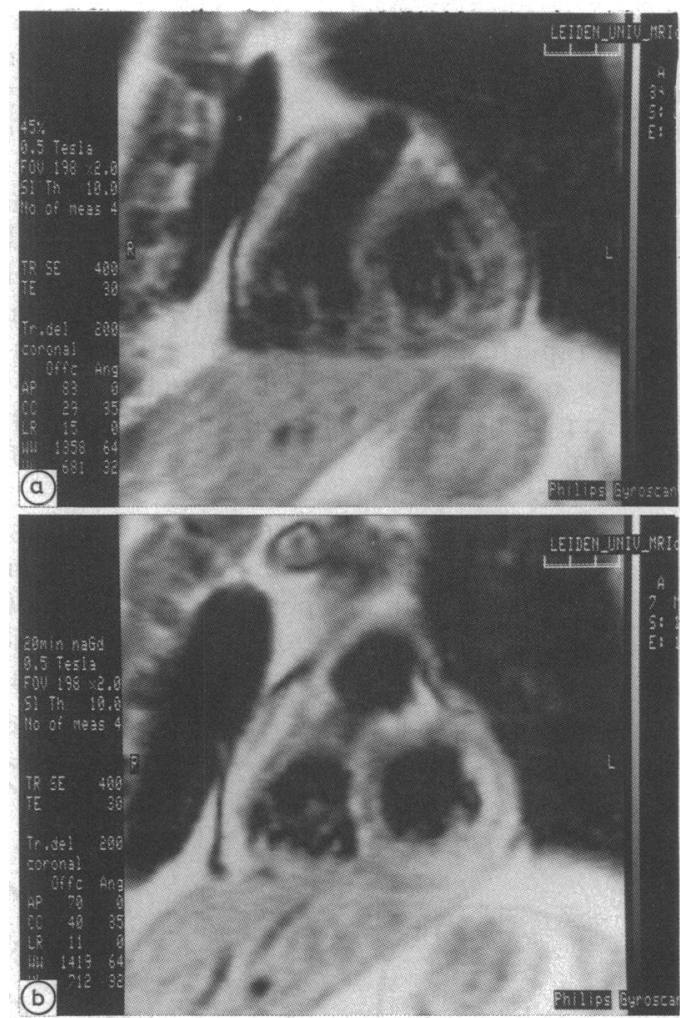

Figure 2 Sagittal image before ( $a$ ) and after (b) administration of Gd-DTPA in a patient with an inferoposterior wall infarction and successful recanalisation of the right coronary artery. Twenty minutes after Gd-DTPA administration homogeneous contrast enhancement (type I) was seen in the inferoposterior region of the myocardium, reportedly representing reperfusion. ${ }^{19}$ Also the non-infarcted segments showed an increase in contrast enhancement. of signal intensities. Signal intensities from the post-contrast images were obtained by region of interest analysis from adjacent myocardial regions, usually 10 per slice (about $1 \mathrm{~cm}^{2}$ per region). Based on the signal intensities obtained, intensity versus region curves were constructed and the region with maximal signal intensity after Gd-DTPA was regarded as representing the infarcted area. Signal intensity ratios were calculated by dividing the maximal signal intensity by the signal intensity from a normal non-infarcted region. Signal intensities were normalised for the increase in the non-infarcted areas, which was shown to be around $20 \%{ }^{23}$ For optimal comparison of changes in the intensity ratios of the pre-contrast and post-contrast images, we selected the regions on the post-contrast image that were similar on the time-activity curve obtained from the pre-contrast image. We also dichotomised our patients according to the morphological appearance of the contrast enhancement based on experimental findings by Peshock et al. ${ }^{19}$ Homogeneous contrast enhancement is considered to represent reperfusion and was called type I in our study (fig 2), and inhomogeneous enhancement, reportedly representing non-reperfusion, was called type II (fig 3).

\section{STATISTICAL ANALYSIS}

Statistical analysis was performed with the multiple $t$ test and Bonferroni's correction.
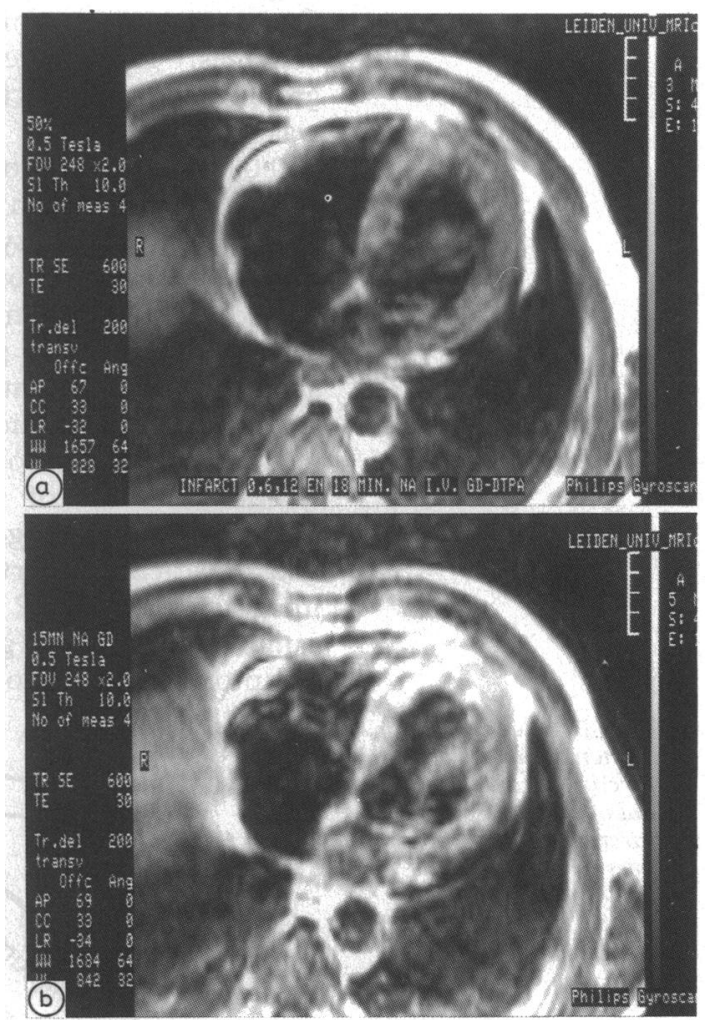

Figure 3 Tranverse image before (a) and after (b) administration of $G d-D T P A$ in a patient with an anteroseptal wall infarction. The left anterior descending coronary artery remained occluded after intracoronary streptokinase. Fifteen minutes after Gd-DTPA administration inhomogeneous contrast enhancement (type II) was seen in the anteroseptal region of the myocardium, reportedly representing non-reperfusion. ${ }^{19}$ myocardium, reportedly representing non-reperfusion
Like figure 2 the non-infarcted segments showed an increase in contrast enhancement. 
Non-parametric correlation analysis was performed with Spearman rank test. A p value of $<0.05$ was considered to be significant. Values are expressed as the mean (SD).

\section{Results}

The table shows the results of thrombolytic treatment and the magnetic resonance imaging findings in each patient. After the administration of Gd-DTPA 24 patients (89\%) showed increased contrast enhancement in the infarcted areas, which improved infarct definition. The site of the region with contrast enhancement always coincided with the infarct site established by the electrocardiogram. Also the non-infarcted areas showed a slight but definite increase of contrast after Gd-DTPA (figs 2 and 3 ). In one patient (case 4 ) no contrast enhancement was seen; this was probably because the infarct was small ( $\alpha$ hydroxybutyrate dehydrogenase release of $105 \mathrm{U} / 1)$. In two patients (cases 3 and 5) poor quality magnetic resonance imaging did not allow adequate visual interpretation. Despite the absence of visually observed contrast enhancement in three patients, all 27 patients showed an increase of computer-assessed intensity ratios after Gd-DTPA $(1 \cdot 15(0 \cdot 17) v$ $1.52(0.29)(p<0.001))$. The area with the computer-assessed maximal signal intensity ratio after Gd-DTPA was always within the areas of maximal signal enhancement by visual assessment.

The intensity ratio before Gd-DTPA in the patients who were studied early (group 1) (1.06 $(0 \cdot 12))$ was not significantly different from that in the patients who were studied late (group 2) $1 \cdot 19(0 \cdot 18)$. After administration of Gd-DTPA patients in group 1 showed intensity ratios of $1.38(0.12)$ and those in group $21.61(0.34)$ $(\mathrm{p}<0.05$ ) (fig 4). There was a significant correlation between time to magnetic resonance imaging and intensity ratio after $\mathrm{Gd}$ DTPA (Spearman rank correlation coefficient: $0.34 ; p<0.05)$.

Infarct size had no significant effect on signal intensities. Before administration of $\mathrm{Gd}$ DTPA the intensity ratios of the patients with small to moderate infarcts ( $\alpha$ hydroxybutyrate dehydrogenase release $<1000 \mathrm{U} / \mathrm{l}$ ) were $1 \cdot 15$ $(0.20)$ and the intensity ratios of the patients with a large infarct size ( $\alpha$ hydroxybutyrate dehydrogenase release $>1000 \mathrm{U} / \mathrm{l})$ were $1 \cdot 14$

Figure 4 Intensity ratio before and after $G d$ -

DTP $A$ administration when magnetic resonance imaging was early (within 72 hours) and when it was late (more than 72 hours after acute onset of symptoms). After $G d$ symptoms
$D T P A$ the intensity ratio in late magnetic resonance imaging was significantly higher than in early magnetic resonance imaging $(p<0.05)$. Within each group the signal intensity ratio increased significantly after $G d-D T P A$ administration $\left(\star_{p}<0.001\right)$. $(0 \cdot 16)(p=N S)$. After administration of GdDTPA the small infarct size group showed

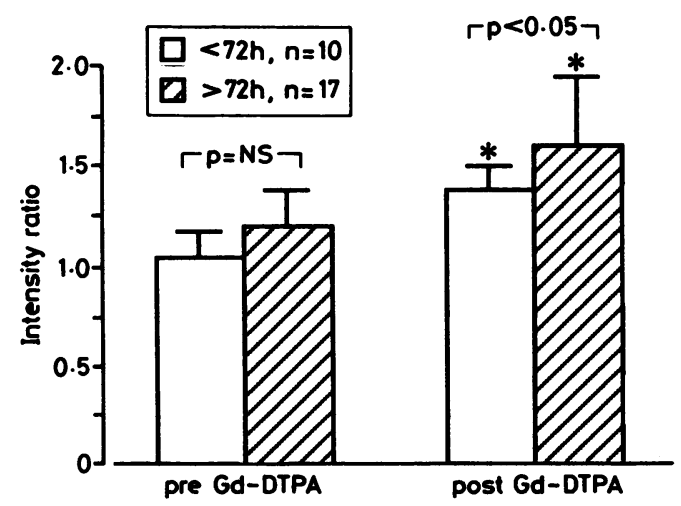

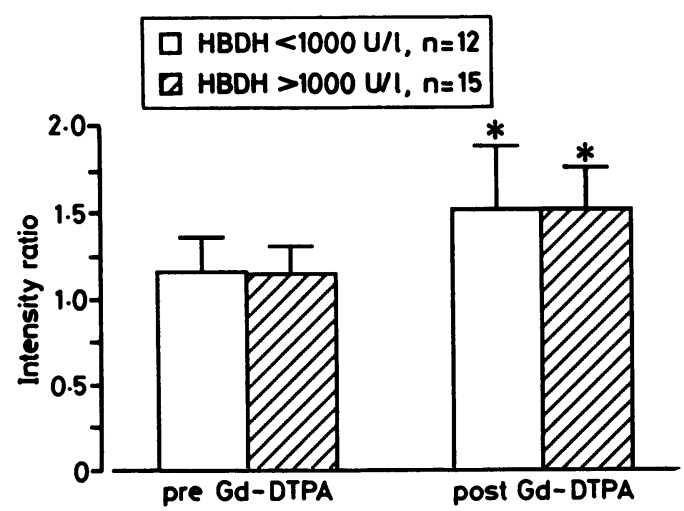

Figure 5 Intensity ratio before and after Gd-DTPA administration in relation to infarct size (small to moderate infarct size (hydroxybutyrate dehydrogenase $(H B D H)$ release $<1000 \mathrm{U}(\mathrm{l})$ ) versus large infarct size (HBDH release $>1000 \mathrm{U} / \mathrm{l}$ ). There was no significant effect of infarct size on signal intensity ratio before or after Gd-DTPA administration. Within each group the intensity ratio increased significantly after $G d-D T P A$ administration $\left(\star_{p}<0.001\right)$.

intensity ratios of $1.52(0.36) v 1.52(0.24)$ ( $p=N S$ ) in the large infarct size group (fig 5 ).

There were no differences in intensity ratios between patients with an anterior wall infarction and those with inferior wall infarction. Before administration of Gd-DTPA the intensity ratios were $1.16(0 \cdot 19)$ and $1 \cdot 13(0 \cdot 16)$ in anterior and inferior wall infarction respectively, and after Gd-DTPA the intensity ratios were $1.62(0.37)$ and $1.42(0.17)$ respectively (both $\mathrm{p}=$ NS) (fig 6).

No differences in intensity ratio were seen between angiographically documented reperfused and non-reperfused myocardial areas after Gd-DTPA. Before Gd-DTPA the intensity ratios were $1 \cdot 16(0 \cdot 18)$ and $1.11(0 \cdot 15)$ respectively $(p=N S)$, and after Gd-DTPA the intensity ratios were $1.51(0.34)$ and 1.55 $(0 \cdot 17)$ respectively ( $p=N S$ ) (fig 7).

Homogeneous contrast enhancement (type I) was seen in five $(26 \%)$ of the 19 patients who showed reperfusion and in one $(12.5 \%)$ of eight patients who did not show reperfusion, indicating that this criterion has a low sensitivity for reperfusion. Although there was inhomogeneous contrast enhancement (type II) in seven $(87.5 \%)$ of eight patients without reperfusion, this was a non-specific phenomenon because it

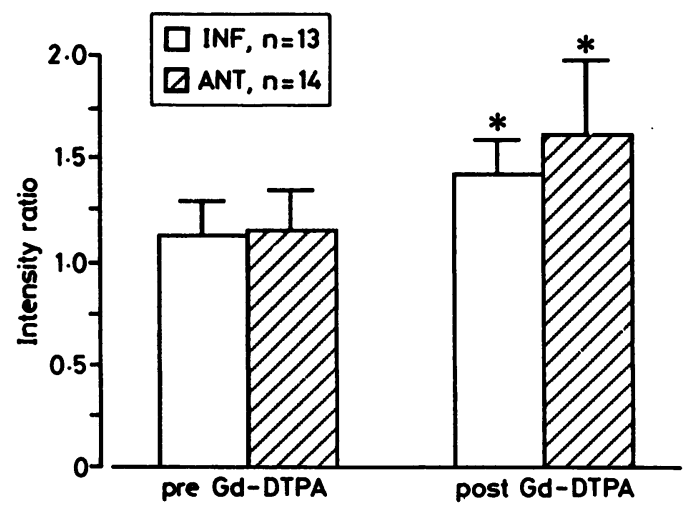

Figure 6 Intensity ratio before and after Gd-DTPA administration in relation to infarct size (inferior versus anterior). There was no significant effect of infarct size on intensity ratio before or after $G d-D T P A$ administration. Within each group the intensity ratio increased significantly after Gd-DTPA administration $\left({ }^{\star} p<0.001\right)$. 
Figure 7 Intensity ratio before and after $G d$ $D T P A$ administration in relation to the effect of thrombolysis (reperfusion versus non-reperfusion). There was no significant effect of thrombolysis on intensity ratio before or after Gd-DTPA administration. Within each group the intensity ratio increased

significantly after $G d$ DTP $A$ administration $\left({ }^{\star} p<0.001\right)$

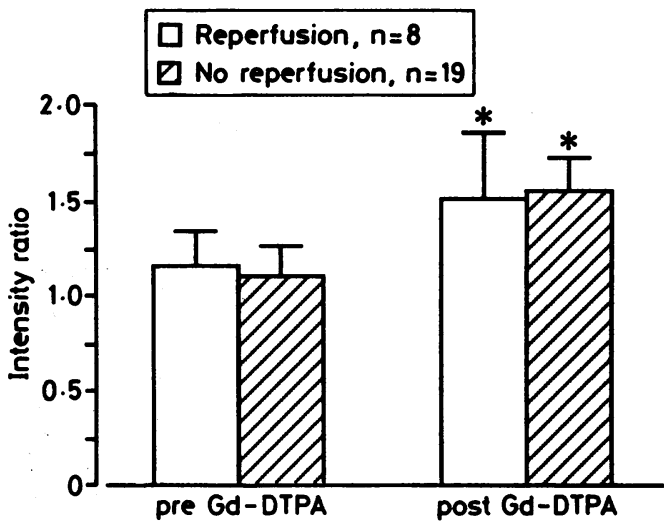

was also seen in $11(56 \%)$ of 19 patients who showed reperfusion.

\section{Discussion}

This study extends our previous findings that the contrast agent Gd-DTPA significantly improves the detection of infarcted myocardium on $T_{1}$ weighted spin echo images. ${ }^{12162021}$ The use of Gd-DTPA as a paramagnetic contrast agent for improving the potential of magnetic resonance imaging to assess coronary artery disease was thoroughly investigated in experimental studies ${ }^{13-15}$. Wesbey et al administered Gd-DTPA to dogs 20 minutes after coronary artery ligation. ${ }^{13}$ Non-ischaemic zones from hearts in dogs injected with GdDTPA showed significantly shorter relaxation times than infarcted zones excised 90 seconds after the adminstration of Gd-DTPA. In contrast, five minutes after injection, infarcted myocardium showed shortened relaxation times while non-infarcted myocardium returned to normal values, suggesting early accumulation in and clearance from normal myocardium and delayed accumulation in and clearance from infarcted myocardium. Administration of Gd-DTPA considerably shortened $T_{1}$ relaxation time in the infarcted areas and so enhances the signal intensity in the infarcted myocardium. In our study, both visual inspection and measurement of signal intensities allowed clear delineation of infarcts on the post-contrast images. Our study also showed increased signal intensity after Gd-DTPA both in the infarcted and non-infarcted areas. These findings accord with those of Eichstaedt et al who used Gd-DTPA to investigate 26 patients after a sustained myocardial infarction. ${ }^{10}$ Eleven patients were imaged 5-10 days after infarction (designated acute infarcts) and 15 patients were imaged later. Signal intensity within areas of acute infarction was increased by an average of $70 \%$ compared with the precontrast images, while the non-infarcted areas showed an average increase of $20 \%$ after GdDTPA. In the remaining 15 patients no significant contrast enhancement was seen after the administration of Gd-DTPA. Since in Eichstaedt et al's study the minimum interval between the onset of infarction and magnetic resonance imaging was five days, it contains no data about the most acute phase of infarction. ${ }^{10}$ In a preliminary study at our hospital, five patients underwent magnetic resonance imaging with Gd-DTPA 2-17 days after myocardial infarction. ${ }^{13}$ The signal intensity ratio of infarcted versus normal myocardium was significantly greater after the administration of $\mathrm{Gd}$ DTPA than before Gd-DTPA. Moreover, the use of Gd-DTPA improved infarct definition and obviated the need for the more time-consuming $T_{2}$-weighted imaging approach. These findings were confirmed in 17 patients with acute myocardial infarction who showed an average increase in signal intensity of $20 \%$ in normal areas and $45 \%$ in infarcted areas. ${ }^{1620}$ Maximal contrast was measured 15-25 minutes after the administration of Gd-DTPA.

A remarkable finding in the present study was the significant enhancement of signal intensity in the infarcted areas of the patients who were studied more than 72 hours after the acute event compared with the signal intensities of those patients who were studied earlier. This suggests greater delivery or slower washout of Gd-DTPA or both in a later stage of the infarction process. The supply of Gd-DTPA most probably depends on the extent of collateral circulation, neovascularisation, and on slow wash-out from the infarct zone caused by cellular damage. These histopathological processes occur later in the course of the healing process of the infarction and this may explain our findings of increased signal intensity at that time. Our data are supported by those of Rehr et al who showed improved detection with Gd-DTPA in experimental acute myocardial infarction; this effect was more prominent in dogs imaged after 4 or 5 days than in those imaged after 1 or 2 days. ${ }^{14}$ Nishimura et al studied 12 patients with acute myocardial infarction by gated magnetic resonance imaging and Gd-DTPA at four different times (on average 5, 12,30, and 90 days) after the acute onset. ${ }^{23}$ The increase of signal intensity in the infarcted areas was $75 \%, 83 \%, 50 \%$, and $17 \%$ respectively. The normal areas showed an average increase of $20 \%$ after GdDTPA on days 5 and 12 .

We found no difference in signal intensity between small and large infarcted areas, based on a cut off point of $1000 \mathrm{U} / 1$ of $\alpha$ hydroxybutyrate dehydrogenase release. Because we used only a few slices per magnetic resonance imaging, an anatomical assessment of infarct size was not performed because the extent of infarction can only be assessed by a multislice imaging technique encompassing the whole left ventricle. We found no difference in signal intensity between anterior and inferior infarcts.

Magnetic resonance imaging with $\mathrm{Gd}$ DTPA did not allow the non-invasive identification of patients with early reperfusion after thrombolytic treatment and those without because we were unable to show differences in signal intensity or in morphological appearance between reperfused and non-reperfused areas. Previous experimental data from McNamara et al had shown that Gd-DTPA significantly shortened $T_{1}$ in myocardial regions with irreversible injury, while no differences in signal intensity or relaxation times were seen in reversibly injured myocardium. ${ }^{18}$ Peshock et al 
showed in dog hearts that contrast enhancement after Gd-DTPA was considerably augmented in reperfused myocardium with a uniform contrast pattern in reperfused hearts and a non-uniform contrast enhancement in non-reperfused hearts. ${ }^{19}$ However, it is difficult to compare our clinical observations with those of earlier experimental studies. ${ }^{17-19}$ Peshock et al performed magnetic resonance imaging immediately after controlled episodes of coronary artery ligation, which in some instances were followed by an hour of reperfusion. ${ }^{19}$ In contrast, in our patients the mean interval between the onset of infarction and magnetic resonance imaging was 93 hours, and only one patient could be studied within 24 hours of acute coronary arteriography. At that time the infarct related arteries may be reoccluded and it is therefore not known whether or not the areas were reperfused during the imaging procedure. Unfortunately, we found it impracticable to study patients earlier after acute coronary arteriography.

The number of patients without reperfusion may have been too small for any differences between them and those who had early reperfusion to be statistically significant but it seems unlikely that a larger sample size would show clinically relevant differences. Been et al found no differences in $T_{1}$ values (without the use of Gd-DTPA) between patients with reperfusion and those without, ${ }^{7}$ suggesting that alterations in $T_{1}$ are complex and do not reflect specific histological findings. Perhaps more accurate magnetic resonance imaging measurements of infarct size may be helpful in distinguishing between reperfused and non-reperfused myocardium, ${ }^{24}$ but appropriate software programs have yet to be developed. Furthermore, determinations of infarct size from the cumulative release of $\alpha$ hydroxybutyrate dehydrogenase have clearly showed that, though the mean infarct size was smaller in patients with successful thrombolytic treatment, there was considerable overlap with patients in whom no recanalisation was achieved. ${ }^{25}$ In the current study we found no significant difference in enzymatically determined infarct size.

Our study shows that Gd-DTPA improves the detection and localisation of infarct zones by magnetic resonance imaging by a $T_{1}$ weighted spin echo sequence in patients treated with thrombolysis for acute myocardial infarction, but is of little if any value in the non-invasive identification of patients in whom thrombolytic treatment was successful. Our finding that maximal contrast enhancement is achieved more than $\mathbf{7 2}$ hours after the onset of acute myocardial infarction is clinically relevant because this suggests that Gd-DTPA enhanced magnetic resonance imaging studies in patients with acute myocardial infarction should be delayed until they are beyond the critical phase of infarction.
1 McNamara MT, Higgings CB, Schechtmann N, et al. Detection and characterisation of acute myocardial infarction in man with the use of gated magnetic resonance. Circulation 1985;71:717-24.

2 Filipchuck NG, Peshock RM, Malloy CR, et al. Detection and localisation of recent myocardial infarction by magnetic resonance imaging. Am J Cardiol 1986;58:214-9.

3 Johnston DL, Thompson RC, Liu P, et al. Magnetic resonance imaging during acute myocardial infarction. Am J Cardiol 1988;57:1059-65.

4 Been M, Ridgeway JP, Douglas RHB, et al. Characterisation of acute myocardial infarction by gated magnetic resonof acute myocardial infarction by gated

5 Underwood SR, Rees RSO, Savage PE, et al. Assessment of regional left ventricular function by magnetic resonance. regional left ventricular functio

6 Canby RC, Reeves RC, Evanochko WT, Elgavish GA, Pohost GM. Proton nuclear magnetic resonance relaxation times in severe myocardial ischemia. J Am Coll Cardiol 1987;10:412-20.

7 Been M, Smith MA, Ridgeway JP, et al. Serial changes in the $T_{1}$ magnetic relaxation parameter after myocardial infarction in man. Br Heart $J 1988 ; 59: 1-8$.

8 Wesbey G, Higgins CB, Lanzer P, Botvinick E, Lipton M. Imaging and characterisation of acute myocardial infarction in vivo by gated nuclear magnetic resonance. Circulation 1984;69:125-30.

9 Fisher MR, McNamara MT, Higgins $\mathrm{CH}$. Acute myocardial infarction. MR-evaluation in 19 patients. $A J R$ 1987;148:247-51.

10 Eichstaedt HW, Felix R, Dougherty FC, Langer M, Rusch $\mathbb{W}$, Schmutzler $\mathbf{H}$. Magnetic resonance imaging in different stages of myocardial infarction using the contras agent Gadolinium-DTPA. Clin Cardiol 1986;9:527-35.

11 Johnston DL, Liu P, Lauffer RB, et al. Use of GadoliniumDTPA as a myocardial perfusion agent: potential applica-
tions and limitations for magnetic resonance imaging. $J$ tions and limitations for mad $1987 ; 28: 871-7$.

12 De Roos A, Doornbos J, Van der Wall EE, Van Voorthuisen AE. MR imaging of acute myocardial infarction: value of Gd-DTPA. AJR 1987;150:531-4.

13 Wesbey GE, Higgins CB, McNamara MT, et al. Effect of Gadolinium-DTPA on the magnetic relaxation times of normal and infarcted myocardium. Radiology 1984;153:165-9.

14 Rehr RB, Peshock RM, Malloy CR, et al. Improved in vivo magnetic resonance imaging of acute myocardial infarction after intravenous paramagnetic contrast agent administration. Am J Cardiol 1986;57:864-8.

15 Nishimura T, Yamada Y, Kozuka T, Nakatani T, Noda H, Takano $H$. Value and limitation of Gadolinium-DTPA contrast enhancement in the early detection of acute contrast enhancement in the early detection of acute

16 Van der Wall EE, Doornbos J, Postema S, et al. Improved detection of myocardial infarction by Gadoliniumenhanced magnetic resonance imaging [Abstract]. Eur Heart J 1988;9(suppl A):340.

17 Tscholakoff D, Higgins CB, Sechtem U, McNamara MT. Occlusive and reperfused myocardial infarcts: effect of Gadolinium-DTPA on ECG-gated magnetic resonance imaging. Radiology 1986;160:515-9.

18 McNamara MT, Tscholakoff D, Revel D, et al. Differentiation of reversible and irreversible myocardial injury by MR imaging with and without Gadolinium-DTPA Radiology 1986;158:765-9.

19 Peshock RM, Malloy CR, Buja M, Nunnally RL, Parkey RW, Willerson JT. Magnetic resonance imaging of acute myocardial infarction: gadolinium diethylenetriamine pentaacetic acid as a marker of reperfusion. Circulation 1986;74:1434-40.

20 Van Dijkman PRM, Doornbos J, De Roos A, et al. Improved detection of acute myocardial infarction by magnetic resonance imaging using Gadolinium-DTPA. Int J Card Imaging 1989;(in press).

21 De Roos A, Van Rossum AC, Van der Wall EE, et al. Reperfused and non-reperfused myocardial infarction: the potential of Gadolinium-DTPA enhanced MR imaging. Radiology 1989;172:717-20.

22 Van der Laarse A, Hermens WTh, Hollaar L, et al. Assessment of myocardial damage in patients with acute Assessment of myocardial damage in patients with acute
myocardial infarction by serial measurement of serum $\alpha$ myocardial infarction by serial measurement of serum $\alpha-$
hydroxybutyrate dehydrogenase (HBDH)-levels. $A m$ hydroxybutyrate dehydro
Heart $J$ 1984;107:248-60.

23 Nishimura T, Yamada N, Takamiya M, et al. Serial assessment of acute myocardial infarction by gated magassessment of acute myocardial infarction by gated magnetic resonance imaging and Gad
tract]. J Nucl Med 1988;29:P802.

24 Wisenberg G, Finnie KJ, Jablonsky G, Kostuk WJ, Marshall $T$. Nuclear magnetic resonance and radionuclide angiographic assessment of acute myocardial infarction in a randomised trial of intravenous streptokinase. $\mathrm{Am}$ Cardiol 1988;62:1011-6.

25 Van der Laarse, A, Vermeer F, Hermens WT, et al. Effects of early intracoronary streptokinase on infarct size estimated from cumulative enzyme release and on enzyme release rate: a randomised trial of 533 patients with acute myocardial infarction. Am Heart $J$ 1986;112:672-81. 